\title{
Internet-Based Interventions for Social Anxiety Disorder - an Overview
}

\author{
Johanna Boettcher ${ }^{\mathrm{a}, \mathrm{b}}$ Per Carlbring ${ }^{\mathrm{b}}$ Babette Renneberg ${ }^{\mathrm{a}}$ Thomas Berger $^{\mathrm{c}}$ \\ ${ }^{a}$ Department of Clinical Psychology and Psychotherapy, Freie Universität Berlin, Germany \\ ${ }^{\mathrm{b}}$ Department of Psychology, Stockholm University, Sweden \\ ${ }^{c}$ Department of Clinical Psychology and Psychotherapy, University of Bern, Switzerland
}

\section{Keywords}

Social anxiety disorder - Internet-based treatment . Cognitive behavior therapy · Review

\section{Summary}

Internet-based interventions hold specific advantages and disadvantages in the treatment of social anxiety disorder (SAD). The present review examines different approaches in the internet-based treatment of SAD and reviews their efficacy and effectiveness. 21 studies investigated the potential of guided and unguided internetbased cognitive-behavioral treatments (ICBT) for SAD, comprising a total of $\mathrm{N}=1,801$ socially anxious individuals. The large majority of these trials reported substantial reductions of social anxiety symptoms through ICBT programs. Within effect sizes were mostly large and comparisons to waitlist and more active control groups were positive. Treatment gains were stable from 3 months to 5 years after treatment termination. In conclusion, ICBT is effective in the reduction of social anxiety symptoms. At the same time, not all participants benefit from these treatments to a sufficient degree. Future research should focus on what makes these interventions work in which patient populations, and at the same time, examine ways to implement internet-based treatment in the routine care for socially anxious patients.

\author{
Schlüsselwörter \\ Soziale Angststörung · Internetbasierte Behandlung · \\ Verhaltenstherapie · Übersichtsarbeit
}

\section{Zusammenfassung}

Die internetbasierte Behandlung der sozialen Angststörung vereint spezifische Vorteile und einige potenzielle Nachteile. Die vorliegende Überblicksarbeit untersucht verschiedene Ansätze der internetbasierten Behandlung sozialer Ängste und überprüft deren Wirksamkeit. Insgesamt haben 21 Studien das Potenzial von internetbasierten verhaltenstherapeutischen Programmen (ICBT) in der Behandlung sozialer Ängste überprüft. Dabei wurden 1801 sozial ängstliche Personen eingeschlossen. Die große Mehrheit dieser Studien berichtete bedeutsame Veränderungen der Symptome der sozialen Angststörung durch die ICBT Programme. Die ermittelten Präpost-Effektstärken waren überwiegend groß und auch der Vergleich zu Wartelisten und aktiveren Kontrollgruppen fiel positiv aus. Die erzielten Behandlungserfolge waren 3 Monate bis 5 Jahre nach Behandlungsende stabil. Schlussfolgernd kann man festhalten, dass ICBT die Symptome der sozialen Angststörung wirksam reduziert. Gleichzeitig profitieren nicht alle Teilnehmer ausreichend von den angebotenen Programmen. Zukünftige Studien sollten sich der Erforschung möglicher Prädiktoren und Wirkmechanismen widmen und gleichzeitig untersuchen, wie internetbasierte Behandlungen in der Routineversorgung eingebunden werden können.

\section{KARGER \\ Fax +497614520714}

Information@Karger.com

www.karger.com (c) 2013 S. Karger GmbH, Freiburg

$1016-6262 / 13 / 0233-0160 \$ 38.00 / 0$

Accessible online at:

www.karger.com/ver
Dr. Johanna Boettcher

Department of Clinical Psychology and Psychotherapy, FU Berlin

Habelschwerdter Allee 45, 14195 Berlin, Germany

johanna.boettcher@fu-berlin.de 


\section{Introduction}

Social anxiety disorder (SAD) is one of the most (if not the most) researched disorder in the field of internet-based treatments. This fact may be explained by the specific advantages that internet-based interventions hold for a patient population that, as evidenced by Erwin and colleagues [2004], found a 'home' on the internet. SAD is characterized by an intense fear of embarrassment and humiliation in social situations. Individuals with SAD are afraid of the judgment and critique of others and avoid relevant situations. SAD is one of the most common mental disorders. Lifetime prevalence rates vary between 6.6 and $12.1 \%$ in Europe and Northern America [Fehm et al., 2005; Kessler et al., 2005]. The majority of individuals with SAD seem to experience a chronic course of social anxiety symptoms: on average, patients with SAD suffer from this disorder for 20-25 years [e.g., Beard et al., 2010; Keller, 2003]. At the same time, SAD is associated with severe impairments in personal, occupational, and educational life. Compared to healthy controls, individuals with SAD are less likely to be married, less likely to finish school, and more likely to be unemployed [Bruch et al., 2003; Stein and Kean, 2000]. They are also more likely to stay in jobs below their level of education [Lampe et al., 2003; Ruscio et al., 2008]. Individuals with SAD often suffer from comorbid mental disorders which further aggravate their psychological well-being and their quality of life [e.g., Fehm et al., 2008]. SAD is not only associated with high personal suffering but also with high societal costs which further emphasizes the need for effective treatments. The German National Health Survey assessed days of absence from work due to disability over the last 12 months. Disability days were much more frequent in persons with SAD than in healthy controls (39.4 days compared to 9.9 days) [Fehm et al., 2005].

Cognitive behavior therapy (CBT) has shown to be effective in the treatment of SAD. The most recent meta-analyses on CBT for SAD reported controlled effect sizes of $d=0.70$ 0.86 [Acarturk et al., 2009; Powers et al., 2008]. In their review, Rodebaugh et al. [2004] estimated that about two thirds of treated patients with SAD experience significant clinical change through CBT. However, although effective treatments exist and many patients benefit from these treatments, the proportion of those who seek treatment is low. Only about $20-40 \%$ of those with SAD consult with a mental health specialist [Gross et al., 2005; Issakidis and Andrews, 2002; Wittchen et al., 1999]. A still lower proportion of about $24 \%$ receive adequate treatment defined as antidepressant medication or CBT [Issakidis and Andrews, 2002]. Treatment rates are lower in rural areas, in individuals with low income, in ethnic minorities, and in individuals over 60 years [Wang et al., 2005a,b]. In a German study, Wittchen and colleagues [1999] reported that treatment rates rise with comorbidity, with only $12 \%$ of those persons with pure SAD receiving help compared to $28 \%$ of those with comorbid SAD. This low treatment rate is certainly partly due to restricted access to healthcare facilities. On the other hand, the disorder's specific fear of social situations offers a further explanation for why it takes individuals with SAD up to 20 years to consult a professional [Keller, 2003]. Olfson and colleagues [2000] found that about $20 \%$ of those individuals with SAD who do not seek treatment avoid this because of their fear what others may think of them.

Internet-based interventions hold the potential to facilitate treatment seeking for individuals with SAD. Socially anxious individuals experience more control and less threat of negative evaluation in online interactions [Lee and Stapinski, 2012; Mazalin and Klein, 2008]. The circumvention of a direct faceto-face contact and the communication via e-mail in internetbased interventions may therefore lower the threshold to actively seek help. At the same time, the lack of face-to-face contact might also be considered as a major disadvantage of internet-based interventions. The remote communication in online treatments might encourage the avoidance of direct interactions and may rob patients of the experience to overcome their anxiety in real-life contact with a therapist. Encouraging avoidance is the exact opposite of what CBT therapists want to achieve in the treatment of anxiety disorders. However, CBT manuals for SAD allow and even recommend some avoidance strategies in the initiation of the therapeutic relationship (e.g., using the flipchart to direct attention away from the patient) in order to make it easier for the patient to engage in the therapeutic process [e.g., Stangier et al., 2006]. Thus, the distant communication in web-based treatments could also be viewed as a means of engaging in a process of change that will ultimately result in a reduction of avoidance of real-life face-to-face interactions.

The potential of internet-based interventions for the treatment of social anxiety has been investigated in numerous empirical trials. The goal of the present review is to summarize these trials and to evaluate the efficacy and effectiveness of different forms of internet-based interventions for SAD. We mainly focus on disorder-specific cognitive-behavioral treatment programs and will then briefly review innovative approaches such as attention bias modification and transdiagnostic approaches. We also explore the relevance of clinician guidance in internet-based cognitive-behavioral treatments (ICBT).

Relevant trials have been identified in a literature search conducted in PsychInfo using the keywords 'social AND (phobia OR anxiety) AND (internet OR web OR online) AND (treatment OR intervention OR self-help OR therapy)' and in discussion with experts in the field of internet-based interventions.

\section{ICBT for SAD}

There are now 4 different ICBT programs evaluated for SAD. 1 program was developed in Sweden ('SOFIE') [Andersson et al., 2006], 1 in Switzerland [Berger et al., 2009], 1 in 


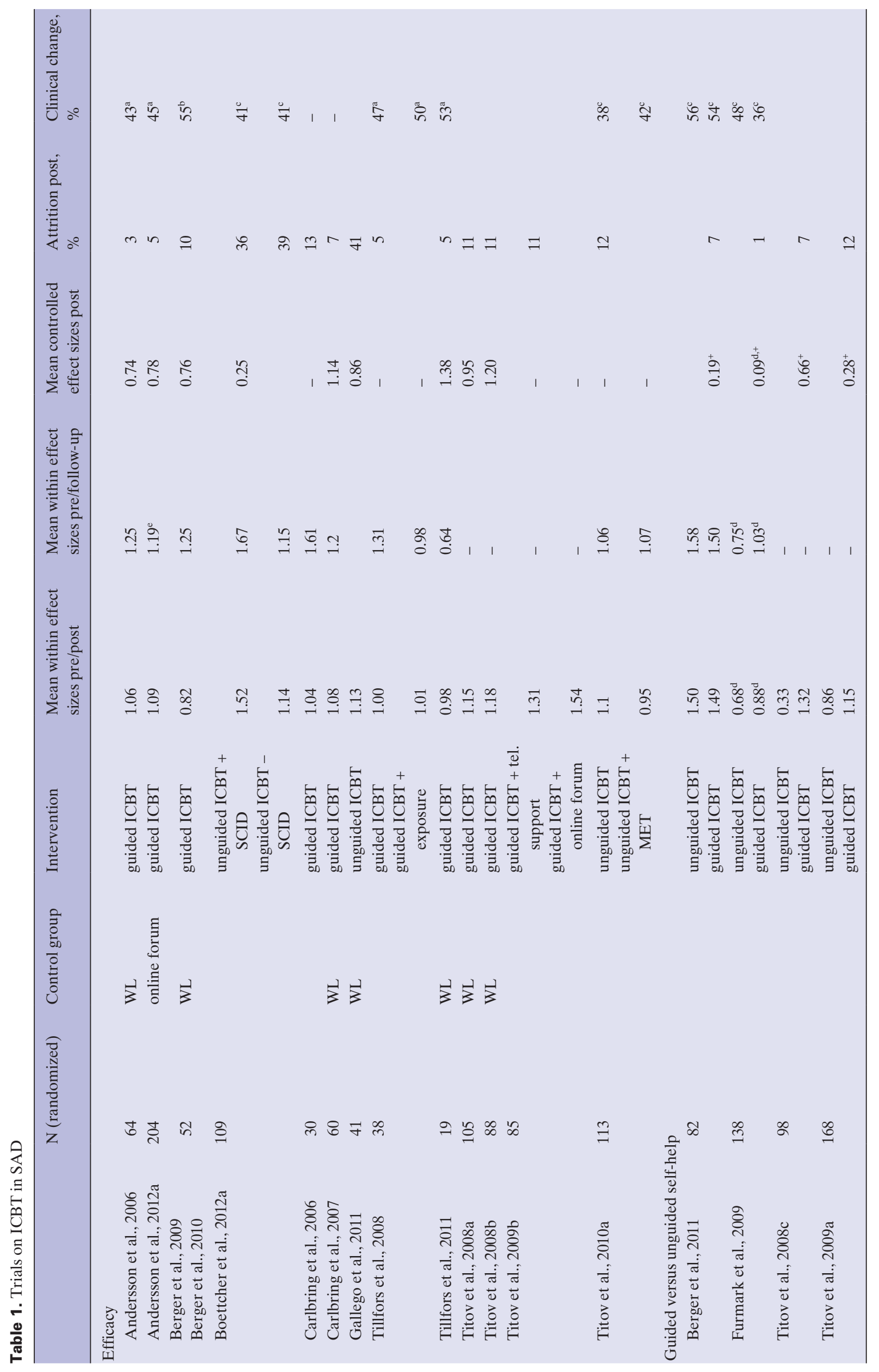




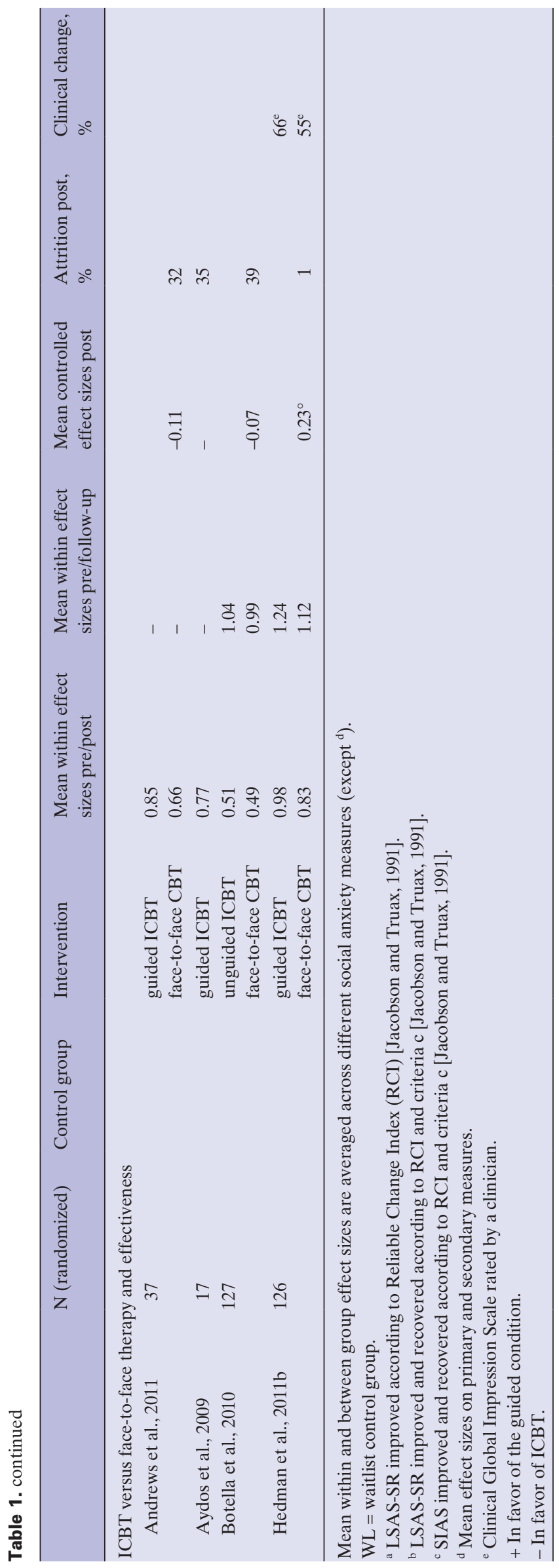

Australia ('Shyness') [Titov et al., 2008a], and 1 in Spain ('Talk to Me') [Botella et al., 2010]. The program of Botella et al. [2010] has a special focus on fear of public speaking. All 4 programs incorporate the core elements of CBT. They include sessions on psychoeducation, cognitive restructuring, and exposure. Most of them also encourage participants to work on self-focused attention, to prepare for and prevent relapses, and to take part in a discussion forum. The programs differ somewhat in the way they present the relevant information and exercises. Whereas the SOFIE program asks the participant to download written pages from a self-help manual, Berger et al. [2009] as well as Botella et al. [2010] include more interactive elements, e.g., videotaped real audiences for public speaking exercises. In the program of Titov et al. [2008a], participants are guided through the Shyness manual by a fictional character who suffered from social fears and overcame his anxiety with the help of a CBT therapist. All programs except Talk to Me encourage participants to use an online discussion forum which is usually moderated or supervised by a clinician. With the exception of Talk to Me, all programs have been evaluated in a guided as well as in an unguided format.

Table 1 summarizes the current state of research on internet-based treatments of SAD. According to our knowledge, 21 studies have been conducted to evaluate the (comparative) efficacy and effectiveness of ICBT, comprising altogether $\mathrm{N}=$ 1,801 socially anxious participants.

\section{Efficacy}

Research started off with trials estimating the efficacy of newly developed programs for the treatment of SAD. The first study was published in 2006 by Andersson and colleagues. Until now, 17 studies have reported results on the efficacy of ICBT (the comparisons with face-to-face therapy are examined separately). Most studies administered more than 1 social anxiety outcome measure. Within and between effect sizes depicted in table 1 are averaged across all effect sizes reported for self-report social anxiety measures at post and follow-up assessment.

With the exception of the open study of Carlbring and colleagues [2006] all studies were randomized controlled trials (RCTs). 7 trials focused on the comparison of internet-based self-help with a waitlist control group [Andersson et al., 2006; Berger et al., 2009, 2010; Carlbring et al., 2007; Gallego et al., 2011; Tillfors et al., 2011; Titov et al. 2008a,b] whereas 1 study compared ICBT to an online discussion group condition [Andersson et al., 2012a]. 8 studies compared different forms of ICBT, 7 of them focusing on different degrees of clinician guidance [Berger et al., 2011; Boettcher et al., 2012a; Furmark et al., 2009; Tillfors et al., 2008; Titov et al., 2008c, 2009a,b]. 1 study examined ICBT with and without Motivational Enhancement Therapy [Titov et al., 2010a]. Mean within effect sizes on self-report social anxiety measures from pre to post assessment varied between $\mathrm{d}=0.33$ and $\mathrm{d}=1.54$. 15 out of the 
17 studies reported large effects of $d>0.80$. Only 2 unguided conditions yielded small to moderate effects [Titov et al., 2008c, 2009a]. In the trials comparing ICBT to a waitlist condition, the controlled effect sizes at post assessment varied between $\mathrm{d}=0.74$ and 1.38. Compared to a more active control condition of an online discussion group, ICBT still fared better with a moderate controlled effect size of $d=0.78$ [Andersson et al., 2012a].

These consistently positive results of mostly large within and between group effect sizes seem even more reliable in consideration of the low attrition rates. In 8 out of the 17 studies, less than $10 \%$ of the participants did not provide post assessment data. Another 7 studies reported attrition rates between $10-13 \% .2$ studies reported a high proportion of attrition of 36-41\% [Boettcher et al., 2012a; Gallego et al., 2011].

\section{Clinical Change}

Not all studies reported data on clinically significant change, and those that did differed in the definition of clinical change and the outcome measures applied. 7 studies described the rates of significant clinical improvement according to the Reliable Change Index [Jacobson and Truax, 1991]. The percentage of participants with an improved state of health measured by the self-report version of the Liebowitz Social Anxiety Scale (LSAS-SR) [Baker et al., 2002] ranged between 36 and 53\%. 6 studies applied the stricter criteria of improvement and recovery [Jacobson and Truax, 1991]. 1 study reported data of the LSAS-SR and 5 analyzed data of the Social Interaction Anxiety Scale (SIAS) [Mattick and Clarke, 1998]. Rates of improvement and recovery varied between 38 and $56 \%$ (table 1).

\section{Maintenance of Treatment Gains}

Eleven studies evaluated the maintenance of treatment gains. Follow-up periods varied between 3 months and 5 years, with most of the studies choosing follow-up periods of 1 year. Overall, treatment gains were stable. Mean pre followup effect sizes were mostly large and ranged between $d=0.64$ and 1.67. In a study on the long-term benefit of ICBT for SAD, Hedman and colleagues [2011a] reported that improvements remained stable for up to 5 years after termination of the treatment. Participants attributed $60 \%$ of the attained improvement to the ICBT program. An important limitation of all these studies is that none of them included a behavioral avoidance test, often considered an important objective outcome measure when treating SAD [Newman et al., 2011].

\section{Effectiveness}

The efficacy of internet-based self-help programs for SAD seems to be established. However, these results are limited to the research context with its specific recruitment procedures, specific therapists, and elaborate exclusion criteria. How does ICBT transfer to the standard clinical routine? 3 studies examined the effectiveness of ICBT for SAD differing in the extent to which they assimilated to the clinical routine setting. 2 of the studies used standard ways of recruitment. Participants were referred by their general practitioner or psychiatrist [Andrews et al., 2011; Hedman et al., 2011b]. Only 1 effectiveness study did not apply detailed inclusion criteria [Andrews et al., 2011]. 2 studies employed therapists who not only worked as researchers [Andrews et al., 2011; Aydos et al., 2009]. All 3 studies reported acceptable effect sizes for the web-based treatments in routine care. Within effect sizes based on intention-to-treat analyses varied between $\mathrm{d}=0.77$ and 0.98 . 2 studies reported increased attrition rates between 27 and $38 \%$, relative to the efficacy trials, whereas 1 study reported a very low attrition rate of $1 \%$. As the study with the lowest attrition rate demonstrated the largest effects, we can safely conclude that ICBT seems to be effective in routine clinical work.

\section{Internet-Based Self-Help Versus Face-to-Face Therapy}

The effect sizes reported in internet-based self-help are comparable to or even exceed effect sizes of face-to-face treatments in SAD (see introduction). However, the comparison of effect sizes derived from different studies is fraught with methodological difficulties. There are 3 studies directly comparing internet-based treatments with face-to-face treatments. Hedman et al. [2011b] compared the guided SOFIE self-help program with 15 sessions of cognitive-behavioral group therapy following the manual of Heimberg and Becker [2002]. Botella et al. [2010] compared their Talk to Me program with individual psychotherapy addressing the same components as the program. Andrews et al. [2011] examined the differential effects of the Shyness program and a group therapy condition where patients met weekly for $4 \mathrm{~h}$. All $3 \mathrm{com}$ parisons resulted in no significant differences between internet-based treatments and face-to-face treatments. In addition, Hedman et al. [2011c] showed that ICBT was more cost-effective than cognitive-behavioral group therapy because ICBT required less therapist resources.

\section{Clinician Guidance}

ICBT seems to be effective in the research context and in routine clinical work, and effects seem comparable to those achieved by face-to-face CBT. Many advantages of internetbased treatments such as the wide availability depend on the amount of clinician time needed to ensure the efficacy of an intervention. To estimate the amount of required guidance and to examine who should provide this guidance is therefore highly relevant for the implementation of internet-based interventions in routine care. In 2 studies, Titov and colleagues [Titov et al., 2009a,b] asked technicians and research assistants to provide feedback for the participants. Participants were encouraged and commended, but no clinical advice was given. The trials resulted in good effects for the non-clinician guidance conditions. Andersson et al. [2012a] investigated whether experienced CBT therapists yielded better results 
than advanced psychology students in treating socially anxious patients online. They did not find a difference in therapeutic outcome, but students needed more time to provide the relevant support. 4 studies directly compared guided and unguided self-help approaches in SAD. In 3 programs, this comparison did not result in any significant differences [Berger et al., 2011; Botella et al., 2010; Furmark et al., 2009]. In a fourth program, the comparison of guided and unguided selfhelp favored the guided approach [Titov et al., 2008c]. However, after enhancing the unguided approach with automatic reminders in a further study, the unguided approach achieved good effects [Titov et al., 2009a]. This line of research emphasizes the importance of prompts and reminders in the work with a self-help program. However, results do not imply that these reminders have to be delivered by trained therapists or that clinician contact is absolutely necessary. Under certain conditions, unguided programs seem to achieve good therapeutic outcome. For example, 1 study examined the effects of clinician contact in the diagnostic phase and found that the participation in a structured diagnostic interview with a clinician did not influence primary outcome but had a beneficial effect on adherence and secondary outcomes [Boettcher et al., 2012a]. A study with panic disorder patients found that working with a clear deadline had a positive effect on treatment outcome [Nordin et al., 2010]. Also, 1 recently conducted study on the transdiagnostic treatment of anxiety disorders (Berger et al., personal communication) found that a good alliance with a guiding clinician was more relevant in programs not specifically tailored to patients' needs. One could conclude that clinician guidance is less important when a proper diagnosis is established and in programs that fit the patients' needs and are clearly structured.

\section{Innovative Approaches}

Rates of clinical change in ICBT for SAD clearly indicate that not all participants benefit from these treatments. The investigation of innovative treatment approaches is therefore highly relevant in order to provide alternatives to existing online treatments. In SAD, the internet-based modification of attention bias has received particular attention. In other disorders, alternative psychotherapeutic approaches such as psychodynamic treatments or acceptance-based interventions have been successfully evaluated [e.g., Hesser et al., 2012; Johansson et al., 2012a]. Another promising approach constitutes the transdiagnostic treatment of anxiety disorders which has been evaluated in different formats in 6 studies.

\section{Attention Bias Modification}

Three RCTs examined the potential of internet-based attention bias modification for the reduction of social fears [Boettcher et al., 2012b; Carlbring et al., 2012; Neubauer et al., 2013]. They were inspired by very positive results of com- puterized brief training procedures in the laboratory setting [Amir et al., 2009; Schmidt et al., 2009]. Such programs aim to target biases in information processing which are thought to be crucial to the maintenance of anxiety disorders including SAD. Attention training programs in the laboratory achieved the targeted reduction of attention bias and led to a large decrease of social fears [e.g., Amir, et al., 2009; Heeren et al., 2012]. In all 3 internet studies, similar programs did not result in a significant change of attention bias. None of the studies found a significant difference between the attention training group and a control group, and changes in social anxiety were only small to moderate. One can conclude that remotely delivered attention training programs are not effective in the treatment of social anxiety.

\section{Transdiagnostic Treatment Approaches}

A recent development in the field of internet-based treatments includes transdiagnostic interventions. These interventions address comorbid and overlapping symptoms, which are common among anxiety disorders and depression [Barlow, 2002]. In contrast, comorbid disorders or subthreshold symptoms are usually ignored in standardized disorder-specific treatments. Until now, 6 studies on different forms of transdiagnostic treatments included patients with SAD. 3 studies evaluated unified treatment approaches [Titov et al., 2010b, 2011; Johnston et al., 2011] and 3 studies examined tailored interventions [Carlbring et al., 2011; Johansson et al., 2012b; (Berger et al., personal communication)]. In unified interventions, the same treatment protocol is used for all patients, regardless of the specific primary diagnosis. The protocol targets common elements of several disorders and is constructed to fit a broader range of patients [Barlow et al., 2004]. In contrast to unified transdiagnostic treatment approaches, tailored interventions do not use the same protocol for all patients but individually prescribe specific treatment modules to patients on the basis of their primary and secondary complaints.

The unified treatment of anxiety disorders and depression showed good effects on generic outcome measures and clinical change rates. In 2 studies, the reduction of specific symptoms of social anxiety was only moderate and lacked behind the effects of disorder-specific programs [Titov et al., 2010b, 2011]. The third and largest study, however, reported results similar to disorder-specific programs and showed large reductions of social anxiety symptoms in patients with SAD [Johnston et al., 2011]. The unified treatment approach was especially beneficial for individuals with comorbid disorders [Johnston et al., 2013]. A tailored treatment for heterogeneous anxiety disorders that allocated specific treatment modules to patients on the basis of a diagnostic interview showed good results in comparison to an online discussion forum group [Carlbring et al., 2011]. A similar tailored program for the treatment of depression and comorbid conditions (including anxiety) was superior to a standard disorder-specific treatment in patients with high comorbidity [Johannson et al., 2012b]. Finally, a tailored treat- 
ment approach which allocated treatment modules to patients on the basis of self-report measures, showed similar good effects compared to standardized disorder-specific treatment (Berger et al., personal communication). In conclusion, both transdiagnostic and disorder-specific internet-based treatments seem effective in the treatment of SAD. Tailored and unified interventions hold additional potential for the treatment of highly comorbid patients.

\section{Discussion}

The current review aimed at examining the potential of internet-based interventions for the treatment of social anxiety. Most studies on web-based interventions in SAD evaluated guided cognitive-behavioral self-help. In summary, these treatments led to large reductions of social anxiety symptoms and treatment gains were stable after treatment termination. Results of ICBT trials are comparable to results achieved in face-to-face CBT for SAD [Acarturk et al., 2009; Powers et al., 2008], a result reflected in the non-inferiority of ICBT to face-to-face therapy in direct comparisons [Andrews et al., 2011; Botella et al., 2010; Hedman et al., 2011b]. Moreover, the efficacy of ICBT does not seem to be limited to the research setting, although effectiveness trials are still rare and are often not fully representative of the routine care setting [Andrews et al., 2011; Aydos et al., 2009; Hedman et al., 2011c]. A first completely naturalistic study in panic disorder published results on all 570 panic patients treated in a routine care internet clinic between 2007 and 2012. Results revealed that clinical change rates were similar to those obtained in RCTs on ICBT programs [Hedman et al., 2013].

The present review suggests that internet-based cognitivebehavioral interventions effectively reduce social anxiety symptoms. At the same time, these interventions, as all other interventions for SAD, do not work perfectly and not for every patient, as is reflected in the clinical change rates of 40 $60 \% .2$ directions of future research evolve from these conclusions. One is the examination of 'what works for whom' in ICBT and the second is the investigation of ways to disseminate internet-based interventions in routine healthcare.

Research on predictors and mechanisms of change in ICBT is still scarce [Andersson et al., 2009]. The question for whom internet-based interventions work has been asked in a review of Nordgreen and colleagues [2012]. The authors examined several patient and process variables as potential predictors of treatment response in ICBT for SAD. None of the studied patient characteristics predicted treatment outcome, with the exception of initial symptoms severity, which correlated with high post-treatment symptom severity. Similarly, Melville and colleagues [2010] reviewed the literature regarding the prediction of drop-out in internet-based interventions and failed to identify any consistent predictors. In contrast, Hedman and colleagues [2012] found that working full time, having chil- dren, and lower levels of depression predicted better treatment outcome in a randomized controlled comparison of ICBT and group CBT. These (conflicting) results on outcome predictors are in line with findings of the literature on face-toface therapy. Repeatedly, single studies of face-to-face CBT for SAD identified specific patient variables that were associated with treatment outcome. However, none of these specific patient characteristics consistently predicted treatment outcome across several studies [Eskildsen et al., 2010].

The investigation of potential mechanisms of change, or the study of what makes interventions work, often differentiates between mechanisms that are common to all psychotherapeutic interventions and specific agents of change of a certain treatment protocol. Important common factors of psychotherapeutic interventions include the therapeutic relationship and patient expectations [Weinberger, 1995]. In a study in which the role of patient expectations in unguided ICBT for SAD was examined, positive outcome expectations were associated with good therapeutic outcome [Boettcher et al., 2013], a finding supported by the study of Hedman et al. [2012]. Nordgreen and colleagues [2012] also found a positive association between expectations and patient adherence in unguided ICBT. The influence of the therapeutic relationship has been examined in guided ICBT for depression and anxiety, including SAD [Andersson et al., 2012b]. The average quality of the working alliance between participants and guiding internet therapists was good, but its influence on therapeutic outcome was small and not significant. This finding contrasts research in face-to-face CBT where the quality of the therapeutic alliance repeatedly predicted treatment outcome [Hoffart et al., 2009; Stangier et al., 2010]. Thus, it seems that some common mechanisms of change might be of equal importance in internet and face-to-face interventions (e.g., expectations) whereas the relevance of other common factors such as the therapeutic relationship has to be reconsidered in internet-based guided self-help interventions. With regard to more specific mechanisms of change, only the influence of psychoeducation has been empirically examined in an internet-based treatment of SAD. Andersson et al. [2012a] found that an increase of knowledge about SAD was positively correlated with treatment outcome. The influence of other hypothesized agents of change in $\mathrm{CBT}$ interventions such as the conduction of behavioral experiments or the modification of self-focused attention has not yet been analyzed in the internet-based setting. Future research should make use of the great potential of internet-based studies to recruit large patient samples and to keep record of patient and therapist behaviors. In most ICBT programs, written patient-therapist interactions and completed self-help materials such as the input of the patients into online diaries are documented and saved. This offers a great opportunity to examine (the interaction of) specific and common mechanisms of change in representative patient samples.

The investigation of predictors and mechanisms of change 
is an important field of future research and has the potential to improve internet-based as well as face-to-face interventions for SAD. At the same time, the present review demonstrated that the existing ICBT programs can be considered as evidence-based in the treatment of social fears. The reviewed results of numerous RCTs encourage the implementation of internet-based interventions in routine care. Other European countries such as UK, Sweden, and the Netherlands already integrated ICBT programs in routine care and adopted different pathways to offer internet-based interventions to patients with SAD. For example, while internet-based self-help is offered as one of several 'low intensity' treatments in a stepped care approach within primary care trusts in UK [Clark, 2011], specialized internet clinics provide ICBT to routine care patients in Sweden [Hedman et al., 2013]. Future research should empirically investigate different pathways to implement ICBT for patients with social anxiety. On the one hand, dissemination pathways should take into account the increased fear and embarrassment of this patient population and aim at lowering these barriers to treatment seeking (e.g., through online self-referral). On the other hand, dissemination pathways should also aim at providing long-term care for the often chronically affected patients with SAD (e.g., through cooperation with general practitioners). Dissemination pathways should also take into account patient preferences. Not all individuals with SAD embrace the opportunity to get treatment online. In their effectiveness trials, Andrews et al. [2011] as well as Hedman et al. [2011b] reported that about half of the patients in routine care preferred ICBT whereas the other half opted for face-to-face therapy. This further emphasizes that internet-based interventions should become part of healthcare for individuals with SAD, not as a substitute for traditional CBT but as an evidence-based alternative.

\section{Disclosure Statement}

The authors declare that there is no conflict of interests concerning this manuscript.

\section{References}

-Acarturk C, Cuijpers P, van Straten A, de Graaf R: Psychological treatment of social anxiety disorder: a meta-analysis. Psychol Med 2009;39:241-254.

-Amir N, Beard C, Taylor CT, Klumpp H, Elias J, Burns $\mathrm{M}$, Chen X: Attention training in individuals with generalized social phobia: a randomized controlled trial. J Consult Clin Psychol 2009;77:961-973.

-Andersson G, Carlbring P, Holmström A, et al.: Internet-based self-help with therapist feedback and in vivo group exposure for social phobia: a randomized controlled trial. J Consult Clin Psychol 2006;74:677-686.

Andersson G, Carlbring P, Berger T, Almlöv J, Cuijpers P: What makes internet therapy work? Cogn Behav Ther 2009;38(suppl 1):55-60.

Andersson G, Carlbring P, Furmark T: Therapist experience and knowledge acquisition in internet-delivered CBT for Social Anxiety Disorder: a randomized controlled trial. PLoS One 2012a;7:e37411.

Andersson G, Paxling B, Wiwe M, et al.: Therapeutic alliance in guided internet-delivered cognitive behavioral treatment of depression, generalized anxiety disorder and social anxiety disorder. Behav Res Ther 2012b;50:544-550.

Andrews G, Davies M, Titov N: Effectiveness randomized controlled trial of face to face versus internet cognitive behaviour therapy for social phobia. Aust N Z J Psychiatry 2011;45:337-340.

Aydos L, Titov N, Andrews G: Shyness 5: the clinical effectiveness of internet-based clinician-assisted treatment of social phobia. Australas Psychiatry 2009;17:488-492.

Baker SL, Heinrichs N, Kim H-J, Hofmann SG: The liebowitz social anxiety scale as a self-report instrument: a preliminary psychometric analysis. Behav Res Ther 2002;40:701-715.

Barlow DH: Anxiety and Its Disorders: The Nature and Treatment of Anxiety and Panic, ed 2. New York, Guilford Press, 2002.

Barlow DH, Allen LB, Choate ML: Toward a unified treatment for emotional disorders. Behav Ther 2004;35:205-230.
Beard C, Moitra E, Weisberg RB, Keller MB: Characteristics and predictors of social phobia course in a longitudinal study of primary-care patients. Depress Anxiety 2010;27:839-845.

Berger T, Hohl E, Caspar F: Internet-based treatment for social phobia: a randomized controlled trial. J Clin Psychol 2009;65:1021-1035.

Berger T, Hohl E, Caspar F: Internetbasierte Therapie der Sozialen Phobie: Ergebnisse einer 6-MonateKatamnese. Z Klin Psychol Psychother 2010;39: 217-221.

- Berger T, Caspar F, Richardson R, Kneubühler B, Sutter D, Andersson G: Internet-based treatment of social phobia: a randomized controlled trial comparing unguided with two types of guided selfhelp. Behav Res Ther 2011;49:158-169.

Boettcher J, Berger T, Renneberg B: Does a pre-treatment diagnostic interview affect the outcome of internet-based self-help for Social Anxiety Disorder? A randomized controlled trial. Behav Cogn Psychother 2012a;40:513-528.

Boettcher J, Berger T, Renneberg B: Internet-based attention training for social anxiety: a randomized controlled trial. Cognit Ther Res 2012b;36:522-536.

Boettcher J, Renneberg B, Berger T: Patient expectations in internet-based self-help for social anxiety. Cogn Behav Ther 2013;DOI:10.1080/16506073.2012.759615.

Botella C, Gallego MJ, Garcia-Palacios A, Guillen V, Banos RM, Quero S, Alcaniz M: An internet-based self-help treatment for fear of public speaking: a controlled trial. Cyberpsychol Behav Soc Netw 2010;13:407-421.

Bruch MA, Fallon M, Heimberg RG: Social phobia and difficulties in occupational adjustment. J Couns Psychol 2003;50:109-117.

Carlbring P, Furmark T, Steczkó J, Ekselius L, Andersson G: An open study of internet-based bibliotherapy with minimal therapist contact via email for social phobia. Clin Psychol 2006;10:30-38.
Carlbring P, Gunnarsdóttir M, Hedensjö L, Andersson G, Ekselius L, Furmark T: Treatment of social phobia: randomised trial of internet-delivered cognitive-behavioural therapy with telephone support. Br J Psychiatry 2007;190:123-128.

Carlbring P, Maurin L, Törngren C, et al.: Individually-tailored, internet-based treatment for anxiety disorders: a randomized controlled trial. Behav Res Ther 2011;49:18-24.

Carlbring P, Apelstrand M, Sehlin H, Amir N, Rousseau A, Hofmann SG, Andersson G: Internetdelivered attention bias modification training in individuals with social anxiety disorder - a double blind randomized controlled trial. BMC Psychiatry 2012;12:66.

Clark DM: Implementing NICE guidelines for the psychological treatment of depression and anxiety disorders: the IAPT experience. Int Rev Psychiatry 2011;23:318-327.

Erwin, BA, Turk CL, Heimberg RG, Fresco DM, Hantula DA: The internet: home to a severe population of individuals with social anxiety disorder? J Anxiety Disord 2004;18:629-646.

Eskildsen A, Hougaard E, Rosenberg NK: Pre-treatment patient variables as predictors of drop-out and treatment outcome in cognitive behavioural therapy for social phobia: a systematic review. Nord J Psychiatry 2010;64:94-105.

Fehm L, Pelissolo A, Furmark T, Wittchen HU: Size and burden of social phobia in Europe. Eur Neuropsychopharmacol 2005;15:453-462.

Fehm L, Beesdo K, Jacobi F, Fiedler A: Social anxiety disorder above and below the diagnostic threshold: prevalence, comorbidity and impairment in the general population. Soc Psychiatry Psychiatr Epidemiol 2008;43:257-265.

Furmark T, Carlbring P, Hedman E, et al.: Guided and unguided self-help for social anxiety disorder: randomised controlled trial. Br J Psychiatry 2009;195: 440-447. 
Gallego MJ, Emmelkamp PM, van der Kooij M, Mees $\mathrm{H}$ : The effects of a Dutch version of an internetbased treatment program for fear of public speaking: a controlled study. Int J Clin Health Psychol 2011;11:459-472.

Gross R, Olfson M, Gameroff MJ, et al: Social anxiety disorder in primary care. Gen Hosp Psychiatry 2005;27:161-168.

-Hedman E, Furmark T, Carlbring P, Ljótsson B, Rück C, Lindefors N, Andersson G: A 5-year follow-up of internet-based cognitive behavior therapy for a social anxiety disorder. J Med Internet Res 2011a; 13:34-43.

-Hedman E, Andersson G, Ljótsson B, Andersson E, Rück C, Mörtberg E, Lindefors N: Internet-based cognitive behavior therapy vs. cognitive behavioral group therapy for social anxiety disorder: a randomized controlled non-inferiority trial. PLoS One 2011b;6:e18001

-Hedman E, Andersson E, Ljótsson B, Andersson G, Rück C, Lindefors N: Cost-effectiveness of internet-based cognitive behavior therapy vs. cognitive behavioral group therapy for social anxiety disorder: results from a randomized controlled trial. Behav Res Ther 2011c;49:729-736.

-Hedman E, Andersson E, Ljotsson B, et al.: Clinical and genetic outcome determinants of internet- and group-based cognitive behavior therapy for social anxiety disorder. Acta Psychiatr Scand 2012;126: 126-136.

-Hedman E, Ljótsson B, Rück C, et al.: Effectiveness of internet-based cognitive behaviour therapy for panic disorder in routine psychiatric care. Acta Psychiatr Scand 2013;DOI:10.1111/acps.12079.

-Heeren A, Reese HE, McNally RJ, Philippot P: Attention training toward and away from threat in social phobia: effects on subjective, behavioral, and physiological measures of anxiety. Behav Res Ther 2012;50:30-39.

Heimberg RG, Becker RE: Cognitive-Behavioral Group Therapy for Social Phobia: Basic Mechanisms and Clinical Strategies. New York, Guilford Press, 2002.

-Hesser H, Gustafsson T, Lundén C, et al.: A randomized controlled trial of internet-delivered $\operatorname{cog}$ nitive behavior therapy and acceptance and commitment therapy in the treatment of tinnitus. J Consult Clin Psychol 2012;80:649-661.

Hoffart A, Borge F-M, Sexton H, Clark DM: The role of common factors in residential cognitive and interpersonal therapy for social phobia: a processoutcome study. Psychother Res 2009;19:54-67.

Issakidis C, Andrews G: Service utilisation for anxiety in an Australian community sample. Soc Psychiatry Psychiatr Epidemiol 2002;37:153-163.

Jacobson NS, Truax P: Clinical significance: a statistical approach to defining meaningful change in psychotherapy research. J Consult Clin Psychol 1991; 59:12-19.

Johansson R, Ekbladh S, Hebert A, et al.: Psychodynamic guided self-help for adult depression through the internet: a randomised controlled trial. PLoS One 2012a; 7:e38021.

Dohansson R, Sjöberg E, Sjögren M, et al.: Tailored vs. standardized internet-based cognitive behavior therapy for depression and comorbid symptoms: a randomized controlled trial. PLoS One 2012b;7: e36905.

Johnston L, Titov N, Andrews G, Spence J, Dear BF: A randomized controlled trial of a transdiagnostic internet-delivered treatment for anxiety disorders. PLoS One 2011;6:e28079.
Johnston L, Titov N, Andrews G, Dear BF, Spence J: Comorbidity and internet-delivered transdiagnostic cognitive behavioural therapy for anxiety disorders. Cogn Behav Ther 2013;DOI:10.1080/1650607 3,2012,753108

Keller MB: The lifelong course of social anxiety disorder: a clinical perspective. Acta Psychiatr Scand 2003;108(suppl 417):85-94.

Kessler RC, Berglund P, Demler O, Jin R, Merikangas KR, Walters EE: Lifetime prevalence and ageof-onset distributions of DSM-IV disorders in the National Comorbidity Survey Replication. Arch Gen Psychiatry 2005;62:593-602.

Lampe L, Slade T, Issakidis C, Andrews G: Social phobia in the Australian National Survey of Mental Health and Well-Being (NSMHWB). Psychol Med 2003;33:637-646.

Lee BW, Stapinski LA: Seeking safety on the internet: relationship between social anxiety and problematic internet use. J Anxiety Disord 2012;26:197-205.

Mattick RP, Clarke JC: Development and validation of measures of social phobia scrutiny fear and social interaction anxiety. Behav Res Ther 1998;36: 455-470.

Mazalin D, Klein B: Social anxiety and the internet: positive and negative effects. E-J Appl Psychol 2008;4:43-50.

Melville KM, Casey LM, Cavanagh DJ: Dropout from internet-based treatment for psychological disorders. Br J Clin Psychol 2010;49:455-471.

Neubauer K, von Auer M, Murray E, Petermann F, Helbig-Lang S, Gerlach AL: Internet-delivered attention modification training as a treatment for social phobia: a randomized controlled trial. Behav Res Ther 2013;51:87-97.

Newman MG, Szkodny LE, Llera SJ, Przeworski A: A review of technology-assisted self-help and minimal contact therapies for anxiety and depression: is human contact necessary for therapeutic efficacy? Clin Psychol Rev 2011;31:89-103.

Nordgreen T, Havik OE, Öst LG, Furmark T, Carlbring P, Andersson G: Outcome predictors in guided and unguided self-help for social anxiety disorder. Behav Res Ther 2012;50:13-21.

Nordin S, Carlbring P, Cuijpers P, Andersson G: Expanding the limits of bibliotherapy for panic disorder: randomized trial of self-help without support but with a clear deadline. Behav Ther 2010;41:267276

Olfson M, Guardino M, Struening E, Schneier FR, Hellman F, Klein DF: Barriers to the treatment of social anxiety. Am J Psychiatry 2000;157:521-527.

Powers MB, Sigmarsson SR, Emmelkamp PMG: A meta-analytic review of psychological treatments for social anxiety disorder. Int J Cogn Ther 2008;1: 94-113.

Rodebaugh TL, Holaway RM, Heimberg RG: The treatment of social anxiety disorder. Clin Psychol Rev 2004;24:883-908.

Ruscio AM, Brown TA, Chiu WT, Sareen J, Stein MB, Kessler RC: Social fears and social phobia in the USA: results from the National Comorbidity Survey Replication. Psychol Med 2008;38:15-28.

Schmidt NB, Richey JA, Buckner JD, Timpano KR: Attention training for generalized social anxiety disorder. J Abnorm Psychol 2009;118:5-14.

Stangier U, Heidenreich T, Peitz M: Soziale Phobien. Weinheim, Beltz, 2006.
Stangier U, Von Consbruch K, Schramm E, Heidenreich T: Common factors of cognitive therapy and interpersonal psychotherapy in the treatment of social phobia. Anxiety Stress Coping 2010;23:289-301.

Stein MB, Kean YM: Disability and quality of life in social phobia: epidemiologic findings. Am J Psychiatry 2000;157:1606-1613.

Tillfors M, Carlbring P, Furmark T, et al.: Treating university students with social phobia and public speaking fears: internet delivered self-help with or without live group exposure sessions. Depress Anxiety 2008;25:708-717.

Tillfors M, Andersson G, Ekselius L, Furmark T, Lewenhaupt S, Karlsson A, Carlbring P: A randomized trial of internet-delivered treatment for social anxiety disorder in high school students. Cogn Behav Ther 2011;40:147-157.

Titov N, Andrews G, Schwencke G, Drobny J, Einstein D: Shyness 1: distance treatment of social phobia over the internet. Aust N Z J Psychiatry 2008a;42:585-594.

Titov N, Andrews G, Schwencke G: Shyness 2: treating social phobia online: replication and extension. Aust N Z J Psychiatry 2008b;42:595-605.

Titov N, Andrews G, Choi I, Schwencke G, Mahoney A: Shyness 3: randomized controlled trial of guided versus unguided internet-based CBT for social phobia. Aust N Z J Psychiatry 2008c;42:1030-1040.

Titov N, Andrews G, Choi I, Schwencke G, Johnston L: Randomized controlled trial of web-based treatment of social phobia without clinician guidance. Aust N Z J Psychiatry 2009a;43:913-919.

Titov N, Andrews G, Schwencke G, Solley K, Johnston L, Robinson E: An RCT comparing effect of two types of support on severity of symptoms for people completing internet-based cognitive behaviour therapy for social phobia. Aust N Z J Psychiatry 2009b;43:920-926.

Titov N, Andrews G, Schwencke G, Robinson E, Peters L, Spence J: Randomized controlled trial of internet cognitive behavioural treatment for social phobia with and without motivational enhancement strategies. Aust N Z J Psychiatry 2010a;44: 938-945.

Titov N, Andrews G, Johnston L, Robinson E, Spence $\mathrm{J}$ : Transdiagnostic internet treatment for anxiety disorders: a randomized controlled trial. Behav Res Ther 2010b;48:890-899.

Titov N, Dear BF, Schwencke G, Andrews G, Johnston L, Craske MG, McEvoy P: Transdiagnostic internet treatment for anxiety and depression: a randomised controlled trial. Behav Res Ther 2011; 9:441-452.

Wang PS, Berglund P, Olfson M, Pincus HA, Wells KB, Kessler RC: Failure and delay in initial treatment contact after first onset of mental disorders in the National Comorbidity Survey Replication. Arch Gen Psychiatry 2005a;62:603-613.

Wang PS, Lane M, Olfson M, Pincus HA, Wells KB, Kessler RC: Twelve-month use of mental health services in the United States: results from the National Comorbidity Survey Replication. Arch Gen Psychiatry 2005b;62:629-640.

Weinberger J: Common factors aren't so common: the common factors dilemma. Clin Psychol 1995;2:45-69.

Wittchen H-U, Stein MB, Kessler RC: Social fears and social phobia in a community sample of adolescents and young adults: prevalence, risk factors and co-morbidity. Psychol Med 1999;29:309-323. 